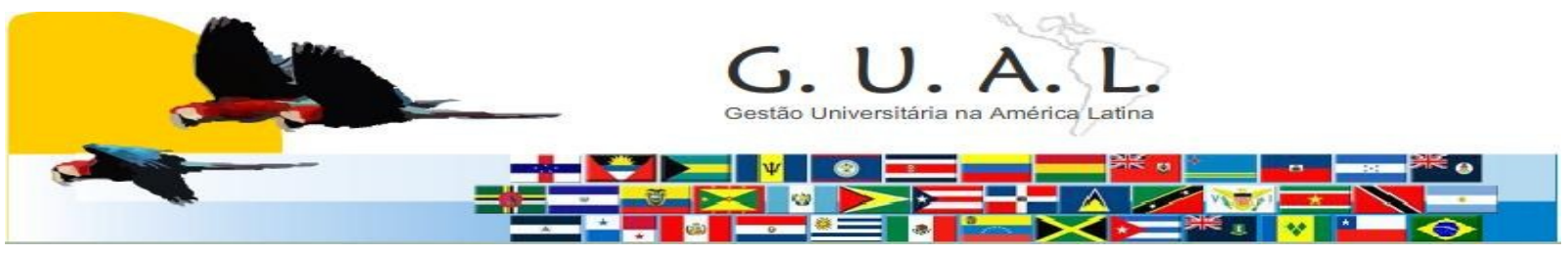

ISSN 1983-4535

\title{
GESTÃO AMBIENTAL EM INSTITUIÇÃO DE ENSINO SUPERIOR - UMA ANÁLISE DA ADERÊNCIA DE UMA INSTITUIÇÃO DE ENSINO SUPERIOR COMUNITÁRIA AOS OBJETIVOS DA AGENDA AMBIENTAL NA ADMINISTRAÇÃO PÚBLICA (A3P)
}

\author{
Silvana Dalmutt Kruger, Mestre \\ Universidade Comunitária da Região de Chapecó \\ - Unochapecó \\ silvanak@unochapeco.edu.br \\ Claudio Luiz de Freitas, Mestre \\ Universidade Federal de Santa Catarina - UFSC \\ clfreitas.sp@gmail.com
}

\author{
Elisete Dahmer Pfitscher, Doutora \\ Universidade Federal de Santa Catarina - UFSC \\ elisete@cse.ufsc.br
}

\author{
Sergio Murilo Petri, Doutor \\ Universidade Federal de Santa Catarina - UFSC \\ smpetri@gmail.com.br
}

\section{RESUMO}

As discussões acerca da sustentabilidade, responsabilidade social e gestão ambiental tem ganhado espaço e repercussão nas últimas décadas. O governo federal enquanto promotor de políticas públicas e ações que pautam o desenvolvimento sustentável, criou a Agenda Ambiental na Administração Pública (A3P). Passível de adesão por todos os entes da públicos, o programa governamental visa alinhar os entes da administração pública as novas práticas que favoreçam o desenvolvimento sustentável. Desta forma a presente pesquisa busca analisar a aderência de uma instituição comunitária de ensino superior a A3P. Para tanto, o estudo de caso, exploratório com abordagem qualitativa adotou a seguinte trajetória metodológica: Inicialmente procedeu-se a revisão de literatura. Em seguida e aplicou-se um check-list junto aos responsáveis pela administração central da instituição e, por fim, procedeu-se a análise de resultados. Tais resultados mostram que a instituição atende aos cinco objetivos propostos. Em relação aos eixos temáticos observa-se a necessidade de melhoria nas ações no que se refere a qualidade de vida dos colaboradores da instituição. Assim como se observa que o gargalo na gestão ambiental da instituição, encontra-se no que se refere às compras sustentáveis, a qual foi identificada como inexistente na organização.

Palavras-chave: Gestão ambiental. Sustentabilidade. Agenda ambiental. A3P. Instituição de ensino superior. 


\section{INTRODUÇÃO}

A discussão sobre gestão ambiental, responsabilidade social e sustentabilidade não é recente e tem ganhado espaço e força nos últimos anos, a partir das exigências de uma sociedade contemporânea, atenta a novos padrões de produção e consumo.

Alinhado as expectativas e anseios dessa sociedade contemporânea, há algum tempo a temática sustentabilidade tem, recorrentemente, sido foco de grandes reuniões mundiais. Nesse sentido, sustentabilidade deixou de ser um diferencial competitivo para assumir o posto de 'palavra de ordem' do momento.

Assim, destaca-se, entre as iniciativas globais voltadas para a temática, a Conferência das Nações Unidas para o Meio Ambiente (ECO-92), que criou a Agenda 21, com o objetivo de propiciar maior respaldo as discussões e ações sobre sustentabilidade, através de diretrizes de planejamento e construção de sociedades sustentáveis.

Ao tratar da construção de sociedades sustentáveis, o agente governamental assume importante papel, seja na elaboração, na execução ou na difusão de ações que permitam o efetivo desenvolvimento sustentável. Cabe ao ente governamental, proporcionar meios para a concretização de tal sustentabilidade.

Nesse sentido, o governo brasileiro, alinhando as diretrizes de sustentabilidade, também para sua atuação e visando a promoção de práticas sustentáveis no cotidiano dos entes públicos, instituiu em 1999, o Programa Agenda Ambiental na Administração Pública (A3P), que, embora não tenha obrigatoriedade legal, tem sido difundida e recomendada para os entes da administração pública.

Observa-se, então, que por ser recomendada aos entes da administração pública a A3P pode e deve ser aderida pelas instituições de ensino superior, vinculadas a administração pública, por serem, estas, centros de difusão do conhecimento e, portanto, entidades credenciadas para transmitir ações e exemplos de sustentabilidade à sociedade, através de suas práticas cotidianas.

Assim, ao se tratar da A3P no âmbito das instituições de ensino superior observa-se uma lacuna nas pesquisas nessa área, conforme evidenciado por Freitas, Borgert e Pfitscher (2011). Assim, tomando por base o referido trabalho, esta pesquisa questiona: Qual o nível de aderência de uma instituição de ensino comunitária a Agenda Ambiental na Administração Pública?

Rev. GUAL., Florianópolis, v. 4, n. 3, p.44-62, set/dez. 2011 
Com base em tal questionamento o presente trabalho busca evidenciar a adesão de uma instituição de ensino comunitária a Agenda Ambiental na Administração Pública (A3P), com base em Freitas, Borgert e Pfitscher (2011).

Para que se possa atingir o objetivo proposto, a presente pesquisa comparará às demandas da A3P as práticas de gestão socioambiental desenvolvidas pela instituição de ensino e cotejará os resultados obtidos por esse resultado com os resultados apresentados por Freitas, Borgert e Pfitscher (2011).

Este estudo está estruturado em cinco seções, da seguinte maneira: Esta seção que apresenta a temática da pesquisa, seguida pela seção 2 , que faz uma breve revisão de literatura. A seção 3 apresenta a trajetória metodológica adotada e a seção 4 contempla os resultados. Por fim, a seção 5 aborda as conclusões e sugestões para novos trabalhos, seguida das referências utilizadas.

\section{REVISÃO DE LITERATURA}

Esta seção aborda a revisão de literatura que sustenta a pesquisa e análise dos resultados. Nesse sentido é apresentado, na sequencia, discussões sobre gestão ambiental e sua inserção no contexto das intituições de ensino e pesquisas já realziadas, assim como aborda-se a Agenda Ambiental na Administração Pública (A3P) e Instituições de ensino.

\subsection{Gestão ambiental}

A temática sustentabilidade tem ganhado força nos últimos anos, seja no contexto prático, de sua aplicação efetiva, seja no contexto teórico através das discussões da acadêmica e da comunidade científica nas mais diversas áreas.

As organizações, em sintonia com a nova e crescente demanda pela sustentabilidade, como maneira de torná-la possível em suas operações cotidianas também tem aderido ao conceito de gestão ambiental.

Nesse sentido, a gestão ambiental é o instrumento responsável por definir, planejar, operacionalizar e executar as ações da organização direcionadas a prevenção e preservação ambiental, além da qualidade e dos impactos ambientais resultantes de suas atividades. (COLEHO, 1996; DIAS, 2006).

O envolvimento da gestão ambiental, com as organizações da esfera pública dá-se, 
além da aplicação dos conceitos válidos para as organizações privadas, através da emissão de normativos com poder de disciplinar, fiscalizar e punir as ações praticadas pelos entes privados; além da atuação no sentido de promover a educação e a qualidade de vida, pautando a gestão ambiental pela harmonia das relações que envolvem o elemento humano, social, econômico e ambiental. (DIAS, 2006; FERREIRA et al, 2008; BONISSONI et al, 2009).

Alguns estudos já foram realizados, pesquisando a gestão ambiental em instituições de ensino. Noeke (2000) pesquisou o sistema de gestão ambiental de uma universidade na Alemanha. Herremans e Allwright (2000) estudaram as iniciativas de gestão ambiental em universidades norte-americanas. Carpenter e Meehan (2002) pesquisaram a gestão ambiental nas universidades da Austrália e Nova Zelândia. Sammalisto e Arvidsson (2005) analisaram a implantação da gestão ambiental nas universidades suecas.

Já Arvidsson (2004) investigou os relatórios de sustentabilidade das universidades suecas, que possuem obrigatoriedade legal de apresentar tais relatórios. Neste mesmo sentido Lozano (2010) pesquisou os relatórios de sustentabilidade de algumas das universidades européias.

No que se refere ao contexto nacional, alguns estudos se destacam, como o de Boff; Oro e Beuren (2008) que pesqusiaram a gestão ambiental de uma Instituição de Ensino Superior; Bolzan; Weber e Löbler (2010) estudaram como são tratados os resíduos sólidos em uma instituição pública. Dziedzic e Dziedzic (2010) pesquisaram o fluxo de materiais em uma universidade de Curitiba, focando na minimização de emissões, consumo de água e energia e produção de esgoto e resíduos. Lima Jr; Oiko e Cavicchioli (2010) estudaram a caracterização, destinação final de resíduos sólidos e avaliação do nível de conscientização dos funcionários da Universidade Estadual de Maringá, quanto ao gerenciamento de resíduos em setores específicos da instituição. Paula e Mendonça (2010) discutiram a importância da atuação socioambiental das IES.

Assim, observando a importância da gestão ambiental no contexto das instituições de ensino superior, com base na literatura nacional e internacional, Freitas, Borgert e Pfitscher (2011) observaram uma lacuna, em relação às Instituições Federais de Ensino Superior e, pesquisando, identificaram, também, a lacuna em relação a Agenda Ambiental na Administração Pública.

Observa-se, então, que tratar de gestão ambiental e sustentabilidade, não se restringe a 
organizações privadas, mas observa-se que sociedade civil, organizações privadas e poder público se complementam na execução e promoção da sustentabilidade. (BERTÉ, 2009)

\subsection{Agenda ambiental na administração pública (A3P)}

A Agenda Ambiental na Administração Pública (A3P) é um programa do Governo Federal, administrado, articulado e desenvolvido pelo Ministério do Meio Ambiente através da Secretaria de Articulação Institucional e Cidadania Ambiental.

A A3P foi desenvolvida sob os pilares da Agenda 21, princípio 8 da Declaração do Rio 92 e na Declaração de Johannesburgo. Tais declarações afirmam que os países devem estabelecer e promover o exame e fixação de novos padrões de sustentabilidade, através de políticas públicas e estratégias que permitam novos referenciais de produção e consumo, bases para o desenvolvimento sustentável.

De acordo com o Ministério do Meio Ambiente - MMA (2011) a A3P, surge como forma de inserir os entes públicos no contexto de gestão ambiental e sustentabilidade, atendendo ao princípio da eficiência, estabelecido pela Carta Magna de 1988 e com reconhecimento da UNESCO.

Tal agenda é pautada por cinco objetivos: (i) sensibilização dos gestores públicos; (ii) promoção da economia de recursos naturais e gastos institucionais; (iii) redução do impacto socioambiental, provocado pelas atividades cotidianas; (iv) contribuição para a revisão dos padrões de produção e consumo, assim como adoção de novos referenciais na administração pública; e (v) melhoria da qualidade de vida. (MMA, 2011)

Nesse sentido, para o efetivo atendimento dos objetivos a que se propõe a A3P, ela estrutura-se em cinco eixos temáticos que norteiam a execução de seus trabalhos. Tais eixos são desenvolvidos com base na na política dos 5R's (Reduzir, Repensar, Reaproveitar, Reciclar, Recusar consumir produtos que gerem impactos socioambientais significativos):

1. Uso racional dos recursos naturais e bens públicos;

2. Gestão adequada dos resíduos gerados;

3. Qualidade de vida no ambiente de trabalho;

4. Sensibilização e capacitação dos servidores;

5. Licitações Sustentáveis. (MMA, 2011)

A adesão a A3P ainda é voluntária, não havendo obrigatoriedade legal, mas recomendações do governo federal e do Ministério do Meio Ambiente, para que tal agenda 
seja adota e implantada nos diversos órgãos da administração pública.

\subsection{Instituições de ensino}

As instituições de ensino são aquelas entidades que tem por atividade a promoção do conhecimento, por meio do ensino. A Carta Magna Federal caracteriza as universidades em seu artigo 207 como àquelas que "gozam de autonomia didático-científica, administrativa e de gestão financeira e patrimonial, e obedecerão ao princípio de indissociabilidade entre ensino, pesquisa e extensão".

Para Costa, Almeida, Freitas (2010, p.2) “a universidade que pratica esse tripé é detentora da grande virtude do compromisso social, pois consegue assimilar as demandas sociais e incorporá-las em seus currículos e ações.” Nesse sentido, Chaui (2003) define universidade como uma instituição social que de certa forma exprime o modo de funcionamento da sociedade como um todo.

Quanto a sua forma de organização as universidades se dividem em públicas, públicas estatais e não-estatais, privadas e ainda um grupo de instituições conhecidas por comunitárias.

Segundo Schmidt e Campis (2009) enquanto o público remete a coletividade, o que pertence a "todos" e tem como subsídio recursos federais, o público estatal refere-se às instituições que tem o controle e subsídio da esfera estadual. Neste olhar, as privadas são aquelas mantidas por entes particulares, sem vínculo ao coletivo ou governamental. As instituições comunitárias são aquelas pertencentes à comunidade, todavia que se mantém com subsídio das mensalidades dos alunos, por não serem reconhecidas como públicas ou privadas, pois possuem gestão democrática com participação da comunidade e o seu patrimônio pertence a esta comunidade, estas entidades são classificadas pelos autores como uma nova categoria: públicas não estatais.

De acordo com Schimidt (2010, p.33) “o entendimento de que público é aquilo que pertence a todos, ao povo, está na raiz do postulado de que o comunitário é uma das formas do público, do público não estatal”. O autor ainda salienta que são traços específicos das instituições comunitárias o patrimônio e os reinvestimentos dos resultados em prol da comunidade, bem como, a inserção regional na comunidade, inclusive com participação desta nos processos decisórios.

Conforme Schimid e Campis (2009) a Associação Catarinense das Fundações 
Educacionais- Acafe, congrega em Santa Catarina 14 Instituições de Ensino Superior. Esse modelo de educação superior contribui para que o Estado de Santa Catarina apresente um dos melhores índices de desenvolvimento humano e ocupe o segundo lugar em matrículas na educação superior no Brasil, segundo dados disponíveis pelo Sistema Acafe (www.universidadecomunitaria.com.br).

Nesse olhar, as particularidades das instituições comunitárias, que iniciaram suas atividades como fundações criadas pela comunidade e poder público, visando o desenvolvimento regional deu origem as discussões de serem consideradas instituições públicas não-estatais, tendo em vista o processo de criação e manutenção.

Para Schmidt (2010, p.29) “A identidade pública não estatal é um aspecto marcante do discurso das comunitárias gaúchas e catarinenses, reafirmado insistentemente nos documentos das instituições e entidades representativas ao longo das últimas décadas."

De certa forma as instituições comunitárias são vistas como privadas do ponto de vista da distribuição de recursos federais ou públicos e pela necessidade da cobrança de mensalidades para sua manutenção, todavia do ponto de vista do conhecimento e compromisso social desempenham o papel que muitas vezes seria do estado.

Pegoraro (2009) salienta o compromisso social da universidade, de produzir conhecimentos e que este não pode ser um bem privado, daí o compromisso das universidades em desenvolver conhecimentos que se traduzem nas competências dos profissionais que ela forma, bem como, o compromisso do Estado que deveria ser voltado às políticas de democratizar o ensino e a inclusão social.

Por isso, entende-se que as instituições de ensino independente da sua forma de organização, devem buscar por meio do ensino, pesquisa e extensão promover conhecimentos capazes de melhorar o meio onde se inserem e servir de modelo para as demais entidades, inclusive com práticas adequadas e responsáveis e prol da sustentabilidade ambiental.

\section{PROCEDIMENTOS METODOLÓGICOS}

O presente estudo possui caráter exploratório, o qual evidencia a partir do Manual da Agenda Ambiental na Administração Pública - Cartilha A3P, as necessidades e considerações a serem observadas pelos gestores nos processos decisórios e de gestão, visando atender os objetivos do estudo. 
O estudo de caso aplicado numa instituição de ensino comunitária, pretende comparar as demandas da A3P com as práticas de gestão ambiental da entidade. Essa instituição de ensino pesquisada está situada na região oeste do Estado de Santa Catarina, no Município de Chapecó, com extensões nos Municípios de São Lourenço do Oeste e Xaxim.

Configura-se como uma instituição de ensino comunitária com uma história de 40 anos no ensino superior. Conforme dados da pesquisa possui cerca de 8.000 alunos, um quadro funcional com 496 docentes e 374 técnico-administrativos. Possui cerca de 40 cursos de graduação, 39 cursos de pós-graduação lato-sensu e três programas de mestrados. Já formou mais de 15.000 profissionais nas mais diversas áreas do conhecimento.

A relevância de sua atuação no contexto regional e considerando-se o compromisso social das instituições de ensino conduz aos objetivos do estudo de identificar se a mesma atende as demandas da A3P com as práticas de gestão ambiental.

A partir da análise documental das exigências da A3P e do check-list proposto por Freitas, Borgert e Pfitscher (2011) realizou-se entrevistas semi-estruturadas junto à vicereitoria de administração da instituição e do responsável pelo viveiro da instituição, os quais responderam ao check-list. Por meio das respostas obtidas foi possível pontuar as ações e práticas da instituição que atendem as exigências da $\mathrm{A} 3 \mathrm{P}$, sendo que para a análise dos resultados a fim de responder aos objetivos propostos, identificou-se duas opções possíveis de serem respondidas: "adere" ou "não adere", caracterizando a análise qualitativa de dados.

O check-list foi analisado com base na percepção dos entrevistados e do pesquisador, por meio das respostas e demais informações coletadas nas entrevistas realizadas, possibilitou identificar a aderência da instituição e as observações que justificam cada questão em relação às exigências da $\mathrm{A} 3 \mathrm{P}$.

\section{ANÁLISE DOS DADOS}

Por meio do check-list proposto por Freitas, Borgert e Pfitscher (2011) verificou junto a instituição de ensino pesquisada se a mesma atende ou não os objetivos e critérios definidos da A3P. A instituição pesquisada atende integralmente aos cinco objetivos da A3P, conforme o Quadro 1. 
Quadro 1 Check-list adesão aos objetivos da A3P

\begin{tabular}{|c|c|c|c|}
\hline $\begin{array}{l}\text { Objetivos da Agenda Ambiental na } \\
\text { Administração Pública (A3P) }\end{array}$ & Adere & $\begin{array}{c}\text { Não } \\
\text { adere }\end{array}$ & Observações \\
\hline \multicolumn{4}{|l|}{ Objetivo 1 - Sensibilização dos gestores } \\
\hline $\begin{array}{l}\text { Há sensibilização dos gestores, em relação à gestão } \\
\text { e responsabilidade socioambiental na instituição? }\end{array}$ & $\mathrm{X}$ & & $\begin{array}{l}\text { Política de gestão } \\
\text { ambiental aprovada no } \\
\text { CONSUN. }\end{array}$ \\
\hline \multicolumn{4}{|c|}{$\begin{array}{c}\text { Objetivo } 2 \text { - Economia de recursos naturais e redução de gastos } \\
\text { institucionais }\end{array}$} \\
\hline $\begin{array}{l}\text { A gestão ambiental na IFES promove o uso racional } \\
\text { de recursos naturais e bens públicos? }\end{array}$ & $\mathrm{X}$ & & $\begin{array}{l}\text { Programa permanente } \\
\text { de conscientização. }\end{array}$ \\
\hline $\begin{array}{l}\text { A gestão ambiental na IFES promove a redução de } \\
\text { gastos institucionais? }\end{array}$ & $\mathrm{X}$ & & $\begin{array}{l}\text { Programa permanente } \\
\text { de conscientização. }\end{array}$ \\
\hline \multicolumn{4}{|c|}{ Objetivo 3 - Redução do impacto socioambiental negativo } \\
\hline $\begin{array}{l}\text { A gestão ambiental na IFES contribui para a } \\
\text { redução de impacto socioambiental negativo, direto } \\
\text { e indireto, provocado pelas atividades } \\
\text { administrativas e operacionais da instituição? }\end{array}$ & $\mathrm{X}$ & & $\begin{array}{l}\text { Programa permanente } \\
\text { de conscientização. }\end{array}$ \\
\hline \multicolumn{4}{|c|}{$\begin{array}{c}\text { Objetivo } 4 \text { - Revisão de padrões de produção e consumo e } \\
\text { adoção de novos padrões de sustentabilidade }\end{array}$} \\
\hline $\begin{array}{c}\text { A gestão ambiental na IFES contribui para a adoção } \\
\text { de novos padrões de sustentabilidade na } \\
\text { administração pública? }\end{array}$ & $\mathrm{X}$ & & $\begin{array}{l}\text { Diretrizes da política de } \\
\text { gestão ambiental: como } \\
\text { edificações com } \\
\text { conceitos de captação } \\
\text { da água da chuva, } \\
\text { rampas de } \\
\text { acessibilidade, etc. }\end{array}$ \\
\hline $\begin{array}{l}\text { A gestão ambiental na IFES contribui para a adoção } \\
\text { e revisão dos padrões de produção e consumo? }\end{array}$ & $\mathrm{X}$ & & $\begin{array}{l}\text { Programas de eficiência } \\
\text { energética, projetos de } \\
\text { reutilização e } \\
\text { reciclagem. }\end{array}$ \\
\hline \multicolumn{4}{|l|}{ Objetivo 5 - Melhoria da qualidade de vida } \\
\hline $\begin{array}{l}\text { A gestão ambiental na IFES contribui para a } \\
\text { melhoria da qualidade de vida dos stakeholders? }\end{array}$ & $\mathrm{X}$ & & $\begin{array}{l}\text { Ex: Redução do } \\
\text { consumo e produção de } \\
\text { lixo. }\end{array}$ \\
\hline
\end{tabular}

Fonte: Adaptado de Freitas, Borgert e Pfitscher (2011)

Observa-se que a instituição de ensino atende aos cinco objetivos do check-list proposto por Freitas, Borgert e Pfitscher (2011), quanto aos objetivos da A3P, sendo que para o primeiro objetivo proposto "sensibilização dos gestores" a instituição possui uma política instituída e aprovada no Conselho Universitário- CONSUN, sendo esta norteadora para as decisões dos gestores. Observou-se durante as entrevistas que a instituição possui uma central 
de resíduos para adequar os destinos de diversos tipos de resíduos gerados, coleta seletiva de lixo e ações de conscientização.

Tal objetivo é considerado por Freitas, Borgert e Pfitscher (2011, p.10) como o de maior relevância entre os demais, "visto que a implantação de um sistema de gestão ambiental está condicionada ao aval dos gestores, especialmente no caso da administração pública e da A3P em que não há obrigação legal para implantação".

Em relação ao segundo e terceiro objetivos quanto à economia de recursos naturais e redução de gastos institucionais e redução do impacto socioambiental negativo os gestores citam um programa permanente de conscientização social e ambiental, além de um exemplo como a compra de energia no mercado livre, o que tem proporcionado redução de gastos mensais e economia no investimento de um novo gerador, justificando a aderência para com este objetivo.

Quanto ao quarto objetivo de revisão de padrões de produção e consumo e adoção de novos padrões de sustentabilidade o gestor entrevistado cita como exemplo as diretrizes da política de gestão ambiental, o qual norteia diversas ações e projetos, e exemplifica as edificações com conceitos de captação e reutilização da água da chuva, rampas de acessibilidade e instalações adequadas aos portadores de necessidades especiais, alem de programas de eficiência energética, projetos de reciclagem e reutilização de materiais, destinação adequada de resíduos.

O quinto objetivo se refere à melhoria da qualidade de vida, neste sentido o objetivo voltado aos stakeholders é contemplado quando os gestores citam programas de conscientização e redução do consumo e produção de lixo, tendo em vista atingir a comunidade acadêmica (acadêmicos, funcionários- professores e técnicos administrativos, manutenção, limpeza, entre outros) e servir de exemplo para as demais entidades.

Em relação aos eixos temáticos da $\mathrm{A} 3 \mathrm{P}$, observa-se que a instituição não adota apenas um dos eixos temáticos propostos, adota parcialmente outro dos eixos e atende integralmente três dos eixos propostos, conforme o Quadro 2.

Quadro 2 - Check-list adesão aos eixos temáticos da A3P

\begin{tabular}{|c|c|c|c|}
\hline $\begin{array}{c}\text { Eixos Temáticos da Agenda Ambiental na } \\
\text { Administração Pública (A3P) }\end{array}$ & Adere & $\begin{array}{c}\text { Não } \\
\text { adere }\end{array}$ & Observações \\
\hline Eixo 1 - Uso racional dos recursos naturais e bens públicos & \\
\hline $\begin{array}{c}\text { A IFES desenvolve alguma ação de } \\
\text { monitoramento/redução do consum o de papel? }\end{array}$ & $\mathrm{X}$ & & $\begin{array}{c}\text { Acompanhamento } \\
\text { semestral. }\end{array}$ \\
\hline
\end{tabular}

Rev. GUAL., Florianópolis, v. 4, n. 3, p.44-62, set/dez. 2011 


\begin{tabular}{|c|c|c|c|}
\hline $\begin{array}{l}\text { A IFES desenvolve alguma ação de } \\
\text { monitoramento/redução do consumo de energia? }\end{array}$ & $\mathrm{X}$ & & $\begin{array}{l}\text { Acompanhamento } \\
\text { semestral. }\end{array}$ \\
\hline $\begin{array}{l}\text { A IFES desenvolve alguma ação de } \\
\text { monitoramento/redução do consumo de água? }\end{array}$ & $\mathrm{X}$ & & $\begin{array}{l}\text { Captação água da } \\
\text { chuva. }\end{array}$ \\
\hline $\begin{array}{c}\text { A IFES desenvolve alguma ação de } \\
\text { monitoramento/redução do consumo de copos } \\
\text { plásticos? }\end{array}$ & $\mathrm{X}$ & & $\begin{array}{l}\text { Sim projeto de } \\
\text { substituição do uso de } \\
\text { copos plásticos. }\end{array}$ \\
\hline $\begin{array}{l}\text { A IFES desenvolve alguma ação de } \\
\text { monitoramento/redução do consumo de outros } \\
\text { materiais/recursos que possam causar impactos } \\
\text { ambientais significativos? }\end{array}$ & $\mathrm{X}$ & & $\begin{array}{l}\text { Central de resíduos } \\
\text { (químicos } \\
\text { principalmente). }\end{array}$ \\
\hline \multicolumn{4}{|c|}{ Eixo 2 - Gestão adequada dos resíduos gerados } \\
\hline A IFES desenvolve e incentiva a política dos 5R's? & $\mathrm{X}$ & & $\begin{array}{c}\text { Programas de } \\
\text { reciclagem e } \\
\text { destinação adequada } \\
\text { de resíduos. }\end{array}$ \\
\hline $\begin{array}{l}\text { A coleta seletiva na IFES atende a resolução } \\
\text { CONAMA } \mathrm{n}^{\circ} 275 \text {, de } 25 \text { de abril de } 2005 ?\end{array}$ & $\mathrm{X}$ & & $\begin{array}{c}\text { Coleta seletiva e } \\
\text { destinação de resíduos } \\
\text { por suas } \\
\text { características. }\end{array}$ \\
\hline $\begin{array}{l}\text { A IFES realiza coleta seletiva solidária nos termos } \\
\text { do Decreto } 5.940 \text {, de } 25 \text { de outubro de } 2006 ?\end{array}$ & $\mathrm{X}$ & & $\begin{array}{l}\text { Possui comissão, e um } \\
\text { setor: Central de } \\
\text { Resíduos para cada } \\
\text { tipo de resíduo. }\end{array}$ \\
\hline $\begin{array}{l}\text { A IFES possui Comissão de Coleta Seletiva } \\
\text { Solidária, nos termos do Decreto 5.940, de } 25 \text { de } \\
\text { outubro de } 2006 ?\end{array}$ & $\mathrm{X}$ & & $\begin{array}{l}\text { Possui comissão, e um } \\
\text { setor: Central de } \\
\text { Resíduos para cada } \\
\text { tipo de resíduo. }\end{array}$ \\
\hline Há destinação adequada a resíduos perigosos? & $\mathrm{X}$ & & $\begin{array}{l}\text { Central de reagentes e } \\
\text { resíduos químicos. }\end{array}$ \\
\hline \multicolumn{4}{|c|}{ Eixo 3 - Qualidade de vida no ambiente de trabalho } \\
\hline $\begin{array}{l}\text { A IFES oferece atividades de ginástica laboral ou } \\
\text { atividades semelhantes aos seus servidores e } \\
\text { bolsistas? }\end{array}$ & $\mathrm{X}$ & & $\begin{array}{l}\text { Programa permanente } \\
\text { de ginástica laboral. }\end{array}$ \\
\hline $\begin{array}{l}\text { A IFES atende a todas as exigências de } \\
\text { acessibilidade, em todas as suas instalações? }\end{array}$ & $\mathrm{X}$ & & Fase de adequações. \\
\hline $\begin{array}{l}\text { A IFES possui preocupação com a ergonomia de } \\
\text { mobiliários e equipamentos de uso dos servidores e } \\
\text { bolsistas? }\end{array}$ & $\mathrm{X}$ & & $\begin{array}{l}\text { Realizado } \\
\text { acompanhamento pela } \\
\text { CIPA. }\end{array}$ \\
\hline $\begin{array}{l}\text { A IFES possui uma comissão interna de prevenção } \\
\text { de acidentes? }\end{array}$ & $\mathrm{X}$ & & CIPA eleita. \\
\hline A IFES possui controle da jornada de trabalho? & $\mathrm{X}$ & & $\begin{array}{l}\text { Ponto eletrônico e } \\
\text { acompanhamento do } \\
\text { banco de horas. }\end{array}$ \\
\hline $\begin{array}{l}\text { A IFES possui grupo especializado/capacitado para } \\
\text { apoio a neuroses (anti-tabagismo, alcoolismo, }\end{array}$ & & $\mathrm{X}$ & $\begin{array}{c}\text { Programa de } \\
\text { conscientização contra }\end{array}$ \\
\hline
\end{tabular}




\begin{tabular}{|c|c|c|}
\hline drogas e neuroses diversas)? & & o alcoolismo. \\
\hline $\begin{array}{l}\text { Os ambientes da IFES, especialmente os de } \\
\text { trabalho, são salubres? }\end{array}$ & $\mathrm{X}$ & $\begin{array}{l}\text { Realizado por } \\
\text { profissionais da } \\
\text { medicina e segurança } \\
\text { do trabalho. }\end{array}$ \\
\hline A IFES possui programa de saúde ocupacional? & $\mathrm{X}$ & Pronto saúde. \\
\hline A IFES possui programa de orientação nutricional? & $\mathrm{X}$ & Pronto saúde. \\
\hline $\begin{array}{c}\text { A IFES incentiva o desenvolvimento e capacitação } \\
\text { de seus servidores através da autonomia das } \\
\text { atividades a serem desenvolvidas? }\end{array}$ & $\mathrm{X}$ & $\begin{array}{l}\text { Programa permanente } \\
\text { integrado as políticas } \\
\text { de RH. }\end{array}$ \\
\hline $\begin{array}{c}\text { A IFES incentiva o desenvolvimento e capacitação } \\
\text { de seus servidores através do aproveitamento das } \\
\text { habilidades individuais e coletivas? }\end{array}$ & $\mathrm{X}$ & $\begin{array}{l}\text { Programa permanente } \\
\text { integrado as políticas } \\
\text { de RH. }\end{array}$ \\
\hline $\begin{array}{l}\text { A IFES incentiva o desenvolvimento e capacitação } \\
\text { de seus servidores através da percepção do } \\
\text { significado do trabalho individual e coletivo? }\end{array}$ & $\mathrm{X}$ & $\begin{array}{l}\text { Programa permanente } \\
\text { integrado as políticas } \\
\text { de RH. }\end{array}$ \\
\hline $\begin{array}{l}\text { A IFES incentiva e promove a integração social } \\
\text { interna e externa, através da ausência de } \\
\text { preconceitos? }\end{array}$ & $\mathrm{X}$ & $\begin{array}{l}\text { Programa permanente } \\
\text { integrado as políticas } \\
\text { de RH. }\end{array}$ \\
\hline $\begin{array}{l}\text { A IFES incentiva e promove a integração social } \\
\text { interna, através da integração de servidores em } \\
\text { áreas comuns e eventos de finalidade integrativa? }\end{array}$ & $\mathrm{X}$ & $\begin{array}{l}\text { Programa permanente } \\
\text { integrado as políticas } \\
\text { de RH. }\end{array}$ \\
\hline $\begin{array}{l}\text { A IFES incentiva e promove a integração social } \\
\text { interna, através do senso comunitário? }\end{array}$ & $\mathrm{X}$ & $\begin{array}{l}\text { Programa permanente } \\
\text { integrado as políticas } \\
\text { de RH. }\end{array}$ \\
\hline $\begin{array}{l}\text { A IFES incentiva e promove a integração social } \\
\text { interna, através da promoção dos relacionamentos } \\
\text { interpessoais? }\end{array}$ & $\mathrm{X}$ & $\begin{array}{l}\text { Programa permanente } \\
\text { integrado as políticas } \\
\text { de RH. }\end{array}$ \\
\hline $\begin{array}{l}\text { A IFES incentiva e respeita a liberdade de } \\
\text { expressão? }\end{array}$ & $\mathrm{X}$ & $\begin{array}{c}\text { Programa permanente } \\
\text { integrado as políticas } \\
\text { de RH. }\end{array}$ \\
\hline A IFES incentiva e respeita a privacidade pessoal? & $\mathrm{X}$ & $\begin{array}{l}\text { Programa permanente } \\
\text { integrado as políticas } \\
\text { de RH. }\end{array}$ \\
\hline $\begin{array}{c}\text { A IFES incentiva e respeita o tratamento } \\
\text { impessoal? }\end{array}$ & $\mathrm{X}$ & $\begin{array}{c}\text { Programa permanente } \\
\text { integrado as políticas } \\
\text { de RH. }\end{array}$ \\
\hline \multicolumn{3}{|c|}{ Eixo 4 - Sensibilização e capacitação dos servidores } \\
\hline $\begin{array}{l}\text { A IFES desenvolve ações de sensibilização e } \\
\text { capacitação com os servidores técnico- } \\
\text { administrativos? }\end{array}$ & $\mathrm{X}$ & $\begin{array}{l}\text { Programa permanente } \\
\text { integrado as políticas } \\
\text { de RH. }\end{array}$ \\
\hline $\begin{array}{l}\text { A IFES desenvolve ações de sensibilização e } \\
\text { capacitação com os servidores docentes? }\end{array}$ & $\mathrm{X}$ & $\begin{array}{l}\text { Programa permanente } \\
\text { integrado as políticas } \\
\text { de RH. }\end{array}$ \\
\hline A IFES desenvolve ações de sensibilização com o & $\mathrm{X}$ & Programas \\
\hline
\end{tabular}

Rev. GUAL., Florianópolis, v. 4, n. 3, p.44-62, set/dez. 2011 


\begin{tabular}{|c|c|c|c|}
\hline \multicolumn{2}{|c|}{ corpo discente? } & & $\begin{array}{c}\text { Metamorfose e Marco } \\
\text { de uma trajetória. }\end{array}$ \\
\hline $\begin{array}{c}\text { A IFES desenvolve ações de sensibilização com a } \\
\text { comunidade no entorno da instituição? }\end{array}$ & $\mathrm{X}$ & $\begin{array}{c}\text { Programa de } \\
\text { orientação } \\
\text { profissional, projetos e } \\
\text { programas de extensão } \\
\text { universitária e de } \\
\text { assistência social. }\end{array}$ \\
\hline $\begin{array}{c}\text { Eixo 5 - Licitações sustentáveis } \\
\text { A IFES incentiva e promove a contratação de obras } \\
\text { públicas que respeitem padrões de } \\
\text { sustentabilidade? }\end{array}$ & & $\mathrm{X}$ & \\
\hline $\begin{array}{c}\text { A IFES incentiva e promove a compra de bens que } \\
\text { respeitem os padrões de sustentabilidade? }\end{array}$ & $\mathrm{X}$ & \\
\hline $\begin{array}{c}\text { A IFES incentiva e promove a contratação de } \\
\text { serviços públicos que respeitem os padrões de } \\
\text { sustentabilidade? }\end{array}$ & $\mathrm{X}$ & \\
\hline
\end{tabular}

Fonte: Adaptado de Freitas, Borgert e Pfitscher (2011)

O primeiro eixo temático se refere ao uso racional dos recursos naturais e bens públicos, observa-se que a instituição atende integralmente as ações propostas pelo Ministério do Meio Ambiente (MMA), e evidencia que pelo acompanhamento semestral das ações a entidade cumpre com o objetivo 2 da A3P.

O segundo eixo evidencia a destinação adequada de resíduos gerados, observa-se que a instituição possui ações de destinação dos resíduos gerados, uma central de resíduos e no caso do lixo orgânico, projeto de coleta seletiva, além de outros projetos como o de substituição de copos plásticos por copos.

O terceiro eixo contempla as condições oferecidas pela instituição, no que se refere à qualidade de vida de seus colaboradores, observa-se que a instituição possui um programa permanente integrado as políticas de recursos humanos, o qual observa a jornada de trabalho com controle digital do ponto, carga horária e condições adequadas, proporciona ginástica laboral, pronto-saúde a disposição dos colaboradores, CIPA constituída e organizada, além do plano de cargos e salários que remunera e valoriza tempo de atuação, titulação e produção científica.

O quarto eixo observa a sensibilização e capacitação dos servidores, neste sentido observou-se que a instituição possui políticas e projetos diferenciados para atender cada grupo, como por exemplo, instituído o plano de cargos e salários para docentes, projetos 
metamorfose e marco de uma trajetória e o programa de orientação profissional para discentes.

O quinto eixo, no entanto, torna-se preocupante, pois se refere às licitações sustentáveis, ou seja, aquisição de obras, serviços e produtos que atendam a padrões adequados de sustentabilidade. Observa-se que a instituição ainda precisa instituir ações e práticas junto aos processos de seleção de fornecedores e critérios para estes, visando a seleção de fornecedores que atendam aos critérios de responsabilidade socioambiental, bem como, tenham processos adequados de sustentabilidade.

Conforme Freitas, Borgert e Pfitscher (2011, p. 11) "em relação às instituições de ensino o MMA reconhece apenas a adesão da Universidade Federal do Rio Grande do Sul”. Neste sentido, observa-se que o estudo colabora com a evidenciação das práticas de gestão ambiental das instituições de ensino conforme as exigências da A3P, evidenciando a importância e necessidade da observação de tal agenda por estas instituições.

Com base nas informações do check-list e nas respostas dos entrevistados, a principal dificuldade da instituição para adesão na integra da A3P está relacionada às práticas de contratação de serviços e fornecedores que atendem as práticas de sustentabilidade.

O estudo de Freitas, Borgert e Pfitscher (2011) enfatiza que as universidades são instituições que produzem discussões e soluções a respeito da temática social e ambiental, e por isso devem estas servir de exemplo e atuarem neste contexto. Neste sentido, atender aos objetivos da A3P torna-se uma forma de efetivarem as práticas sociais e ambientais.

\section{CONCLUSÕES}

O estudo evidencia por meio da análise da adesão de uma instituição de ensino comunitária, as diretrizes da Agenda Ambiental na Administração Pública (A3P), propostas pelo Ministério do Meio Ambiente (MMA).

Considerando-se o check-list desenvolvido por Freitas, Borgert e Pfitscher (2011) o estudo buscou informações junto à uma instituição de ensino superior identificando se a mesma atende aos critérios propostos.

Pode-se observar que a instituição de ensino atende todos os objetivos propostos, todavia, atende parcialmente os critérios estabelecidos em cada eixo quanto as recomendações do MMA, para implantação da A3P, salienta-se ainda, que a mesma possui diversas ações

Rev. GUAL., Florianópolis, v. 4, n. 3, p.44-62, set/dez. 2011 
desenvolvidas em prol do meio ambiente e da comunidade, visando reduzir os impactos ambientais causados pelo decorrer de suas atividades.

Observou-se que a instituição atende integralmente o primeiro eixo temático se refere ao uso racional dos recursos naturais e bens públicos, bem como, evidencia que ocorre acompanhamento semestral das ações da entidade.

Quanto à destinação adequada de resíduos gerados, proposto pelo segundo eixo, a instituição atende ao critério e cita-se que possui ações de destinação dos resíduos gerados, uma central de resíduos e no caso do lixo orgânico, projeto de coleta seletiva, além de outros projetos como o de substituição de copos plásticos por copos.

O terceiro eixo contempla as condições oferecidas pela instituição, no que se refere à qualidade de vida de seus colaboradores, a pesquisa evidencia que a instituição possui um programa permanente integrado as políticas de recursos humanos. O quarto eixo observa a sensibilização e capacitação dos servidores, neste sentido a instituição possui políticas e projetos diferenciados para atender cada grupo (docentes, discentes, técnicos administrativos), como o plano de cargos e salários, projetos metamorfose e marco de uma trajetória e o programa de orientação profissional para discentes.

O quinto eixo, refere-se às licitações sustentáveis, ou seja, aquisição de obras, serviços e produtos que atendam a padrões adequados de sustentabilidade. Embora a instituição não tenha obrigação destes processos, observou-se que a instituição precisa avançar na seleção de fornecedores que atendam aos critérios de responsabilidade socioambiental, bem como, tenham processos adequados de sustentabilidade.

Diante de tais resultados, observa-se a necessidade de adequação das práticas da universidade, para promoção da gestão ambiental e da conseqüente sustentabilidade ambiental da organização.

Observa-se ainda, que embora a instituição atenda parcialmente as diretrizes da A3P, somente a partir da sensibilização dos gestores e, conseqüentemente, dos demais colaboradores da instituição é que ter-se-á condições propícias para o desenvolvimento de ações e implantação efetiva da agenda ambiental na instituição.

Assim, para continuidade das pesquisas alinhadas a essa temática, recomenda-se o aprofundamento da temática, através do estudo pormenorizado e aprofundado do 
desenvolvimento da agenda através de cada eixo específico, assim como a confirmação de sua efetividade, através da replicação do estudo em circunstâncias passíveis de comparabilidade.

\section{REFERÊNCIAS}

ARVIDSSON, K. Environmental management at Swedish universities. International Journal of Sustainability in Higher Education. Hamburg, v.5, n. 1, 2004, p. 91-99, 2004.

BERTÉ, R. Gestão socioambiental no Brasil. São Paulo: Saraiva, 2009.

BOFF, L. M; ORO, I. M; BEUREN, I.M. Gestão ambiental em Instituição de Ensino Superior na visão de seus dirigentes. Revista de Contabilidade da UFBA. Salvador, v.2, n.1, p. 4-13, 2008.

BOLZAN, L. M; WEBER, J. I; LÖBLER, M. L. Alinhamento ambiental em uma Instituição Pública de Ensino Superior. In: ENCONTRO INTERNACIONAL SOBRE GESTÃO EMPRESARIAL E MEIO AMBIENTE. 12., 2010, São Paulo. Anais...São Paulo: FEA/USP, 2010 .

BONISSONI, R.M. et al. A gestão ambiental de uma fábrica de bebida energética por meio da sustentabilidade ambiental. In: CONGRESSO UFSC DE CONTROLADORIA E FINANÇAS. 3., 2009, Florianópolis. Anais...Florianópolis: Departamento de Ciências Contábeis/UFSC, 2009.

CARPENTER, D; MEEHAN, B. Mainstreaming environmental management: Case studies from Australasian universities. International Journal of Sustainability in Higher Education. Hamburg, v. 3, n. 1, p. 19-37, 2002.

CHAUI, M. A universidade pública sob nova perspectiva. Conferência de abertura da $26^{\mathrm{a}}$ reunião anual da ANPED. Poço de Caldas, 05 de out. 2003. Disponível em:

$<$ http://www.anped.org.br/reunioes/26/marilenachauianped2003.doc > Acesso em: 25 ago. 2011.

COELHO, C.C.S.R. A questão ambiental dentro das indústrias de Santa Catarina: Uma abordagem para o segmento industrial têxtil. 1996. 210f. Dissertação (Mestrado) Universidade Federal de Santa Catarina, Florianópolis, 1996.

COSTA, M. P.; ALMEIDA, M.O.D.P ; FREITAS, T. S. Ensino, pesquisa e extensão: Compromisso social das universidades. Disponível em:

$<$ http://www.uftm.edu.br/upload/ensino/tcc teresinha.pdf $>$ Acesso em: 25 ago. 2011.

DIAS, R. Gestão ambiental: Responsabilidade social e sustentabilidade. São Paulo: Atlas, 2006.

DZIEDZIC, M; DZIEDZIC, R. Diagnóstico e proposta de redução de emissões - Campus Universidade Positivo. In: ENCONTRO NACIONAL SOBRE GESTÃO EMPRESARIAL E MEIO AMBIENTE. 12., 2010, São Paulo. Anais... São Paulo: FEA/USP, 2010. 
FERREIRA, L. F. et al. Contabilidade ambiental sistêmica. In: CONGRESSO UFSC DE CONTROLADORIA E FINANÇAS. 2., 2008, Florianópolis. Anais... Florianópolis: Departamento de Ciências Contábeis/UFSC, 2008.

FREITAS, C. L; BORGERT, A; PFITSCHER, E. D. Agenda Ambiental na Administração Pública: Uma análise da Aderência de uma IFES as diretrizes propostas pela A3P. Florianópolis, 16p. Trabalho não publicado.

HERREMANS, I; ALLWRIGHT, D. E; Environmental management systems at North American universities: What drives good performance? International Journal of Sustainability in Higher Education. Hamburg, v. 1, n. 2, p. 168-181, 2000.

LIMA JR., F.R; OIKO, O. T; CAVICCHIOLI, F.F. Gestão de resíduos em universidade: Caracterização e análise da destinação de resíduos sólidos. In: ENCONTRO NACIONAL SOBRE GESTÃO EMPRESARIAL E MEIO AMBIENTE. 12., 2010, São Paulo. Anais...São Paulo: FEA/USP, 2010.

LOZANO, R. The state of sustainability reporting in universities. International Journal of Sustainability in Higher Education. Hamburg, v. 12, n. 1, p. 67-78, 2011.

MINISTÉRIO DO MEIO AMBIENTE. Cartilha A3P: Agenda ambiental na administração pública. 5. ed. Brasília: Ministério do Meio Ambiente, 2009.

. A3P: Agenda ambiental na administração pública. Brasília, 2011b. Dísponível em: $<$ http://www.mma.gov.br/sitio/index.php?ido=conteudo.monta\&idEstrutura $=36>$ Acesso em: 30 jul. 2011.

NOEKE, J. Environmental management systems for universities: A case study. International Journal of Sustainability in Higher Education. Hamburg, v. 1, n. 3, p. 237-251, 2000.

PAULA, L. S; MENDONÇA, J. R.C. A Gestão socioambiental no setor educacional, o papel social das Instituições de Ensino Superior-IES: Um estudo de múltiplos casos em instituições de Pernambuco. In: ENCONTRO INTERNACIONAL SOBRE GESTÃO EMPRESARIAL E MEIO AMBIENTE. 12., 2010, São Paulo. Anais...São Paulo: FEA/USP, 2010.

PEGORARO, L. Universidade e sociedade: sistema catarinense de educação superior. Atos de pesquisa em educação - ppge/me furb. Issn 1809-0354 v. 4, no 3, p. 357-406, set./dez. 2009.

SAMMALISTO, K; ARVIDSSON, K. Environmental management in Swedish higher education Directives, driving forces, hindrances, environmental aspects and environmental co-ordinators in Swedish universities. International Journal of Sustainability in Higher Education. Hamburg, v. 6, n. 1, p. 18-35, 2005.

SCHMIDT, J. P.. O Comunitário em tempos de público não estatal. Avaliação, Campinas; Sorocaba, SP, v. 15, n. 1, p. 9-40, mar. 2010. 
SCHMIDT, J. P; CAMPIS, L. A. C.. Instituições Comunitárias: instituições públicas não estatais. Santa Cruz do Sul: EDUNISC, 2009.

SISTEMA ACAFE. Disponível em: $<$ http://www.universidadecomunitaria.com.br $>$ Acesso em: 28 ago. 2011. 


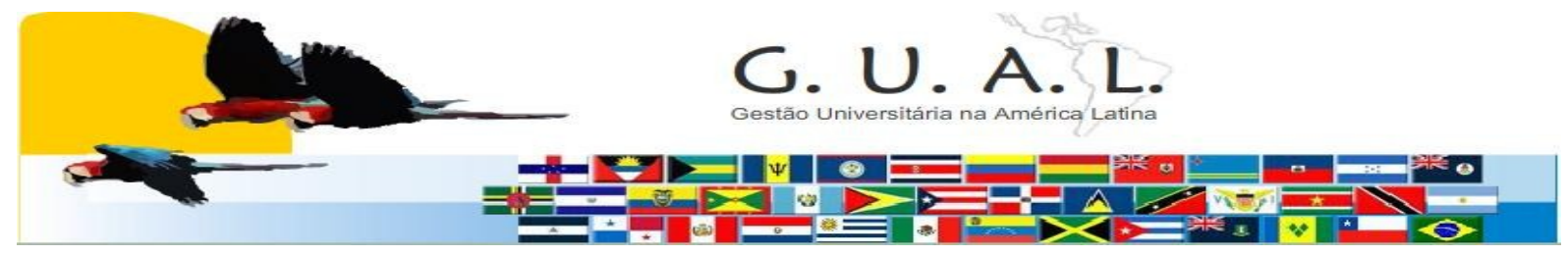

ISSN 1983-4535

\title{
ENVIRONMENTAL MANAGEMENT IN AN INSTITUTION OF HIGHER EDUCATION - A REVIEW OF THE GRIP OF AN INSTITUTION OF HIGHER EDUCATION COMMUNITY OBJECTIVES OF THE ENVIRONMENTAL AGENDA IN PUBLIC ADMINISTRATION (A3P)
}

\author{
Silvana Dalmutt Kruger, Master \\ Universidade Comunitária da Região de Chapecó \\ - Unochapecó \\ silvanak@unochapeco.edu.br
}

Claudio Luiz de Freitas, Master

Universidade Federal de Santa Catarina - UFSC

clfreitas.sp@gmail.com

\author{
Elisete Dahmer Pfitscher, Doctor \\ Universidade Federal de Santa Catarina - UFSC \\ elisete@cse.ufsc.br
}

Sergio Murilo Petri, Doctor

Universidade Federal de Santa Catarina - UFSC smpetri@gmail.com.br

\begin{abstract}
Discussions about sustainability, social responsibility and environmental management has gained importance and impact in recent decades. The brazilian government as a promoter of public policies and actions that guide sustainable development, created the Environmental Agenda in Public Administration (A3P). Open to accession by all entities of the public, the government program aims to align the public administrations of new practices that promote sustainable development. Thus this research seeks to analyze the adherence of a Community institution of higher education A3P. For this, the case study, exploratory andr qualitative approach has adopted the following methodology course: Initially we proceeded to review the literature. Then and applied with a checklist for those responsible for central administration of the institution and, finally, we proceeded to the analysis of results. These results show that the institution meets the five goals.Regarding the themes there is the need for improvement in the actions regarding the quality of life of employees of the institution. As it is observed that the bottleneck in the environmental management of the institution, is in relation to sustainable procurement, which was identified as non-existent in the organization.
\end{abstract}

Keywords: Managemant environmental. Sustainability. Environmental agenda. A3P. Universitys. 